\title{
Application of a Quasi in-situ Experimental Approach to Estimate 3-D Pitting Corrosion Kinetics in Stainless Steel
}

DOI:

10.1149/2.0381613jes

\section{Document Version}

Accepted author manuscript

Link to publication record in Manchester Research Explorer

\section{Citation for published version (APA):}

Almuaili, F., Mcdonald, S., Withers, P., \& Engelberg, D. (2016). Application of a Quasi in-situ Experimental Approach to Estimate 3-D Pitting Corrosion Kinetics in Stainless Steel. Electrochemical Society. Journal/J E S, 163(13), C745-C751. https://doi.org/10.1149/2.0381613jes

\section{Published in:}

Electrochemical Society. Journal|J E S

\section{Citing this paper}

Please note that where the full-text provided on Manchester Research Explorer is the Author Accepted Manuscript or Proof version this may differ from the final Published version. If citing, it is advised that you check and use the publisher's definitive version.

\section{General rights}

Copyright and moral rights for the publications made accessible in the Research Explorer are retained by the authors and/or other copyright owners and it is a condition of accessing publications that users recognise and abide by the legal requirements associated with these rights.

\section{Takedown policy}

If you believe that this document breaches copyright please refer to the University of Manchester's Takedown Procedures [http://man.ac.uk/04Y6Bo] or contact uml.scholarlycommunications@manchester.ac.uk providing relevant details, so we can investigate your claim.

\section{OPEN ACCESS}




\title{
Application of a Quasi In Situ Experimental Approach to Estimate 3-D Pitting Corrosion Kinetics in Stainless Steel
}

\author{
F. A. Almuaili, ${ }^{\text {a,z }}$ S. A. McDonald, ${ }^{\text {b }}$ P. J. Withers, ${ }^{\text {b }}$ and D. L. Engelberg ${ }^{a}$ \\ ${ }^{a}$ Corrosion and Protection Centre, School of Materials, The University of Manchester, Manchester M13 9PL, \\ United Kingdom \\ ${ }^{b}$ Manchester X-ray Imaging Facility, School of Materials, The University of Manchester, Manchester M13 9PL, \\ United Kingdom
}

\begin{abstract}
Pitting corrosion kinetics of type 304L stainless steel have been obtained using a quasi in-situ X-ray computed tomography (X-ray CT) approach. A miniature electro-chemical cell was constructed to allow imaging during potentio-dynamic polarization of a wire specimen. The formation of three discrete pits was observed, allowing comparison between real pit geometry and different geometrical assumptions to estimate pit growth kinetics. The pit volumes obtained by X-ray CT showed good fit with the volume of metal dissolution calculated using Faraday's law. Large fluctuations of the mean current density were observed during the pit nucleation stage, followed by pit growth with mean current densities of $1-3 \mathrm{~A} . \mathrm{cm}^{-2}$. Stability products associated with these pits were on the order of 0.3-0.6 A.m ${ }^{-1}$, with diffusivity parameter (D. $\Delta$ C) of $1.68-3.04 \times 10^{-8}$ mol.cm ${ }^{-1} . \mathrm{s}^{-1}$. Diffusion coefficients for stable pit growth of $0.83-0.96 \times 10^{-5} \mathrm{~cm}^{2} . \mathrm{s}^{-1}$ were estimated for metal ion concentrations of $4.2 \mathrm{M}$.

(C) 2016 The Electrochemical Society. [DOI: 10.1149/2.0381613jes] All rights reserved.
\end{abstract}

Manuscript submitted February 23, 2016; revised manuscript received September 8, 2016. Published 00 0, 2016.

Pitting or crevice corrosion can occur on stainless steels exposed to halide containing environments. The breakdown of the passive surface film results in the nucleation of local attack, which is followed by pit growth, with a number of mechanisms proposed for each stage. ${ }^{1,2}$ Electrochemical polarisation above the critical pitting potential leads to nucleation of pits, in the form of localised metal dissolution, with corrosive electrolyte developing inside the nucleated pit due to hydrolysis of dissolved metal ions, and chloride ions being attracted from bulk solution to maintain charge neutrality. ${ }^{3}$ At high applied electrochemical potentials, pits grow with a polished inner surface morphology, associated with salt film formation, whereas pits grown at lower applied potentials display more irregular etch morphologies of the internal pit surface. ${ }^{4}$ An undercutting mechanism was suggested for pit growth at high electrochemical potentials, leading to the development of dish shaped pits covered by metal lacy covers. ${ }^{5-10}$

Pit propagation is controlled by diffusion of species through the salt film at the inner surface of pits. A high anodic dissolution rate, which facilitate critical ion concentrations inside a pit, is criterion for pits to propagate. ${ }^{11}$ The anolyte concentration inside a pit influences pit growth kinetics and the pit shape. For example, a $3 \mathrm{M}$ concentration of dissolved metal ions was proposed as minimum concentration to turn an open hemispherical meta-stable pit into a stable pit. However, pits developed with lacy metal covers grow at far lower metal ion concentrations, since these covers are believed to provide an effective diffusion barrier ${ }^{12}$ and an increased ohmic resistance between pit interior and the bulk electrolyte. ${ }^{1}$ Based on these observations for the transition between meta-stable and stable pits, the "pit stability product" $\left(0.3 \mathrm{~A} . \mathrm{m}^{-1} \leq \mathrm{i} . \mathrm{r} \leq 0.6 \mathrm{~A} . \mathrm{m}^{-1}\right)$ was proposed, with the latter based on the evolution of pit current density (i) and pit depth (r). ${ }^{12}$

To sustain stable pit growth under anodic polarisation, a minimum current density is required, with typical values for stainless steel in the region of $1-5 \mathrm{~A} . \mathrm{cm}^{-2} \cdot{ }^{13,14}$ For pit initiation, however, far higher current densities were observed, followed by a reduction with increasing pit volume which corresponds to an increase in active pit surface area over time. The electrochemical potential at the pit bottom remains above the repassivation potential resulting in active dissolution conditions. Therefore, initial pit growth studies suggested that associated kinetics were potential dependent under charge transfer control, resulting in a hemispherical pit shape. After the formation of a salt film inside the pit due to limited solubility of cations, pit propagation is considered to be under diffusion-control and potential independent, where the pit shape changes into more elongated dish shape over time. The sides of the pit, typically referred to as lobes, grow faster than the bottom part. Furthermore, due to this mechanism the pit ratio

${ }^{\mathrm{z}}$ E-mail: fahd.almuaili-2@postgrad.manchester.ac.uk (depth vs. width) can change, suggesting that pits grow in depth occurs under diffusion control, with ohmic resistance controlling lateral pit growth. ${ }^{7}$ Typical current densities between $1-2 \mathrm{~A} . \mathrm{cm}^{-2}$ are related to the precipitated salt film at the bottom of the pit, whereas, salt film free regions (side walls) show a maximum current in the range of 3-5 A. $\mathrm{cm}^{-2}$.

The growth kinetics of a single pit in type 304 stainless steel under potentiostatic polarisation control in $1 \mathrm{M} \mathrm{NaCl}$ with $0.4 \mathrm{M} \mathrm{Na}$ thiosulfate solution showed parabolic behavior. ${ }^{15}$ Pit volumes measured by means of mechanical grinding and sectioning followed by optical microscopy showed a good fit with the dissolved volume determined by current measurements using Faraday's law and assuming a hemispherical pit shape. The study also showed that pit growth under potentiostatic control in $3.5 \%$ wt $\mathrm{NaCl}$ and seawater was similar to pits grown under open circuit conditions in $1 \mathrm{M} \mathrm{FeCl}_{3}$ solution, both indicating an exponential relation of pit growth with time. ${ }^{16}$

One dimensional (1-D) pit growth investigations using pencil electrodes ${ }^{26}$ and two-dimensional (2-D) pit geometry estimated using thin foils and in-situ recording or radiography images ${ }^{9}$ have been used to allow estimation of pit stability product. These methods allow pits underneath the metal surface to be observed, but the developed pit shape does not necessarily represent pit growth in 3-D. The effect of constraining pits to grow in 1-D or 2-D may not accurately reflect 3-D growth kinetics. It may affect transport processes of dissolved metal ions between pit anolyte and the bulk solution, which can subsequently affect local pit chemistry and associated growth dynamics.

For pencil electrode (1-D) measurements, pit growth occurs in depth by maintaining a constant surface area related to the diameter of the pencil electrode ${ }^{14,17,18}$. These 1-D studies revealed transition of pit growth kinetics from ohmic/dissolution control to diffusion control at high potentials. A transition current density between both growth regimes in the region of $1-5 \mathrm{~A} . \mathrm{cm}^{-2}$, with the latter a function of the chloride concentration inside the pit, was also observed. ${ }^{14}$ Potential step experiment with 1-D electrodes further revealed the effect of $\mathrm{Cr}$ content and solution chemistry on the dissolution and passivation kinetics, suggesting that salt film precipitation controls the metal dissolution rate. ${ }^{18}$ The effect of electrolyte species also has a profound effect on pit growth kinetics with, for example, the addition of sulfate to $\mathrm{NaCl}$ environment significantly reducing the current density for pit growth. ${ }^{19}$ In this study, pit chemistry was determined based on the minimum concentration at the pit surface that maintains pit growth without passivation. The dissolved metal salt concentration was then estimated by assuming a constant diffusion coefficient (D), yielding diffusivity parameters (D. $\Delta$ C) of 3-3.5 $\times 10^{-8} \mathrm{~mol} . \mathrm{cm}^{-1} . \mathrm{s}^{-1}$ for $\mathrm{NaCl}$, and $2 \times 10^{-8}$ mol.cm ${ }^{-1} . \mathrm{s}^{-1}$ for $\mathrm{NaCl}$ with sulfate. ${ }^{19}$ Pistorius and Burstein also reported a reduction of current density in presence of sulfate for stable pitting on type 304 stainless steel. ${ }^{20}$ 
The aim of our study was to develop an experimental methodology to investigate $3 \mathrm{D}$ pitting corrosion kinetics during exposure to bulk electrolyte, by using a miniature 3-electrode electrochemical cell 2 combined with quasi in-situ X-ray computed tomography (X-ray CT). 53 The second goal was to obtain 3D pit growth kinetics, and compare 4 those to literature reports of pit growth in 2D and 3D, obtained from experiments using miniature capillary probes. 177 Prior to polarisation, the open circuit potential (OCP) was monitored

A solution annealed type 304L stainless steel wire with a diameter of $500 \mu \mathrm{m}$ was used in this study, with a chemical composition of (wt\%) $18.4 \mathrm{Cr}, 8.7 \mathrm{Ni}, 0.02 \mathrm{C}, 1.4 \mathrm{Mn}, 0.34 \mathrm{Si}, 0.04 \mathrm{~N}, 0.03 \mathrm{P}$ and $0.001 \mathrm{~S}$. Short wire sections of $70 \mathrm{~mm}$ were cut and manually ground using 1200 grit $\mathrm{SiC}$ paper, followed by a rinse in deionised water. The surface of the wire was coated with beeswax exposing a cylindrical surface area of $2.83 \mathrm{~mm}^{2}$.

The wire section was mounted vertically in a miniature electrochemical cell shown in Figure 1a, and the set-up was then placed in a ZEISS Xradia Micro tomography instrument (Figure 1b). The diameter of the cell was $24 \mathrm{~mm}$, consisting of a lower part containing the electrolyte with a volume of approximately $9 \mathrm{ml}$ for electrochemical polarisation measurements, and an upper part with a straining rig for applying a tensile load along the length of the wire. The latter was used in another study to investigate the effect of strain on pit growth kinetics and for assessing the nucleation of stress corrosion cracking. The bottom part of the cell housed a miniature reference electrode

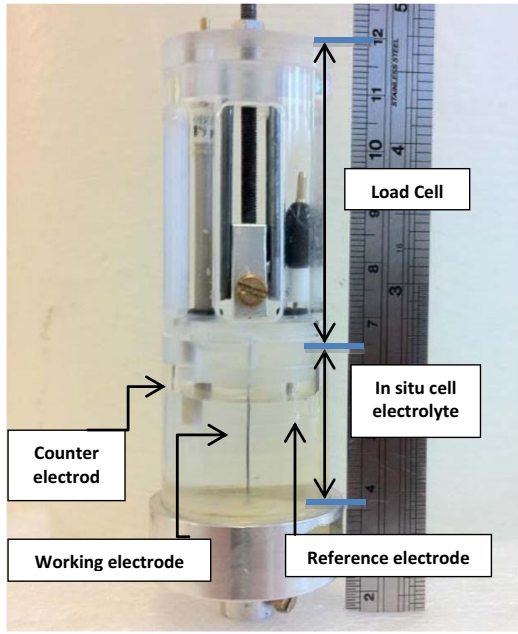

(a)

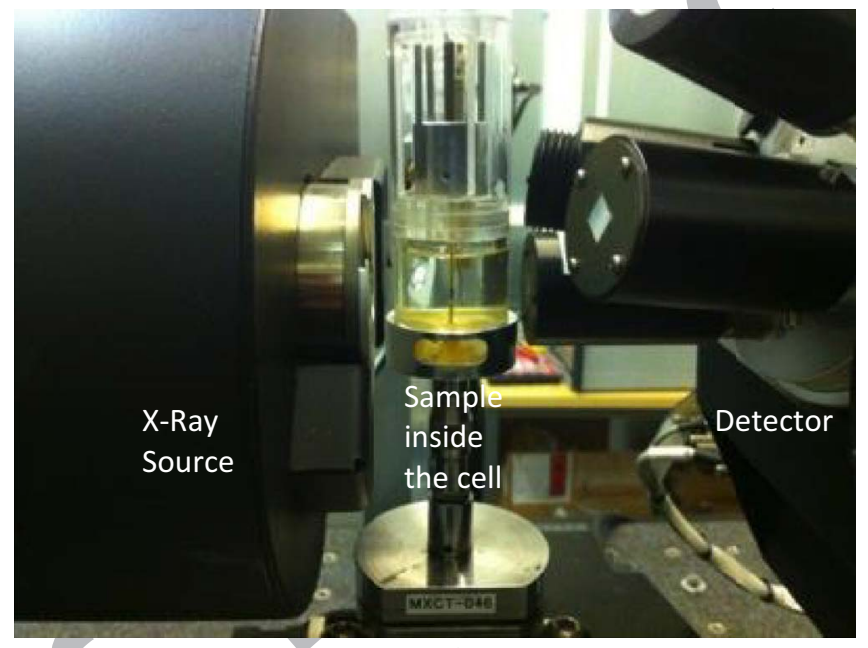

(b)

Figure 1. (a) Photo of the miniature electrochemical cell with capability to apply strain for in-situ X-ray tomography experiments with a type $304 \mathrm{~L}$ wire sample, (b) in-situ cell during an X-ray CT experiment.

for $15 \mathrm{~min}$. The current response was recorded during the polarisation 178 experiment at a rate of $1 \mathrm{~Hz}$

Table I gives a summary of the in-situ experiment with associated polarisation cycles. After each cycle, one X-ray CT scan was performed to visualise the progress of pitting corrosion over time. X-ray

\section{Table I. Summary of in-situ electrochemical polarisation experiment.}

$\begin{array}{ll}\text { Step } & \text { Polarisation Cycles } \\ 0 & \text { X-ray CT scan (reference / without electrolyte) } \\ 1 & \text { OCP measurement (15 min.) } \\ 2 & \text { Potentio-dynamic polarisation from OCP to } 644 \mathrm{mV} \text { vs. } \\ & \text { Ag/AgCl } \\ 3 & \text { X-ray CT scan 1 at OCP } \\ 4 & \text { OCP measurement (5 min) } \\ 5 & \text { 2nd potentio-dynamic polarisation from OCP to } 2644 \mathrm{mV} \\ 6 & \text { vs. Ag/AgCl } \\ 7 & \text { X-ray CT scan 2 at OCP } \\ 8 & \text { OCP measurement (5 min) } \\ 9 & \text { 3rd potentio-dynamic polarisation from OCP to } 700 \mathrm{mV} \text { vs. } \\ & \text { Ag/AgCl } \\ & \text { X-ray CT scan (3) at OCP }\end{array}$



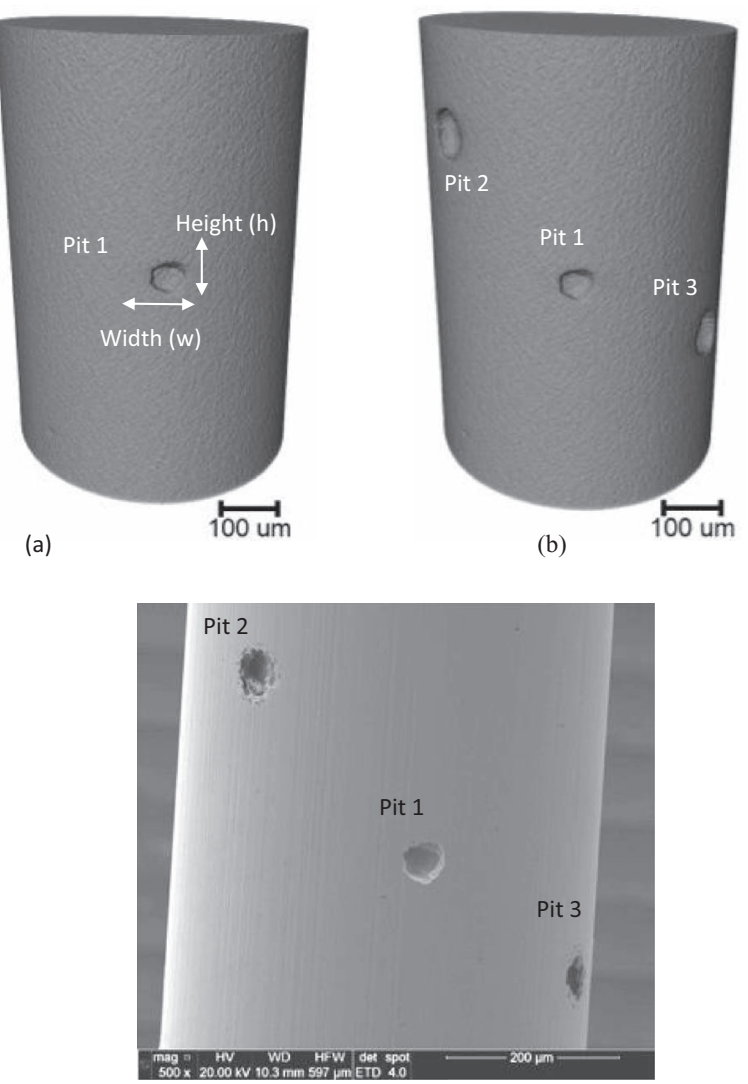

(c)

Figure 2. (a) Reconstructed $\mathrm{X}$-ray $\mathrm{CT}$ data volume of the wire after the $1^{\text {st }}$ electrochemical polarisation scan, (b) X-ray CT data volume after the $2^{\text {nd }}$ potentio-dynamic polarisation cycle, and (c) SEM image of the wire sample with the three pits.
CT scans were recorded at OCP, with each scan taking approximately 2-3 hrs. The sample remained in the solution throughout the whole experiment. For the X-ray CT measurements an accelerating voltage of $120 \mathrm{kV}$ was used, and 721 projections recorded with $2 \times 2$ binning. This resulted in a reconstructed voxel size of $1.83 \mu \mathrm{m}$, with a field of view of $2300 \mu \mathrm{m} \times 2300 \mu \mathrm{m}$.

The data was reconstructed using a Feldkamp-Davis-Kress (FDK) approach, ${ }^{31}$ and images were segmented and visualised using Avizo software. After segmentation of each pit, the total volume, total pit surface area, pit depth, width, height, aspect ratio and shape were obtained. The pit depth, width and height were obtained by using 2-D slices of the 3-D data-set taken from the geometrical pit centre. This approach provided a snap-shot of pit dimensions after each polarisation cycle, with the current response recorded during the polarisation experiment providing in-situ pit growth information. The wire was then removed from the in-situ cell after step 9 (Table I), rinsed in water and images of the pits obtained using a FEI Quanta 650 scanning electron microscope (SEM).

\section{Results and Discussion}

The first X-ray CT scan (step 0) was recorded before the sample was exposed to the electrolyte, to obtain reference data of the investigated wire volume. This scan confirmed that no corrosion or mechanical damage (e.g. cracks) was present before the sample was polarised. After completing this scan, the $\mathrm{NaCl}$ electrolyte was introduced into the in-situ cell. The $1^{\text {st }}$ potentio-dynamic polarisation (step 2 in Table I) resulted in the formation of one corrosion pit (pit 1), with the $2^{\text {nd }}$ potentio-dynamic scan (step 5 in Table I) leading to the nucleation and growth of two new pits (pit 2 and 3). Figure 2 a shows

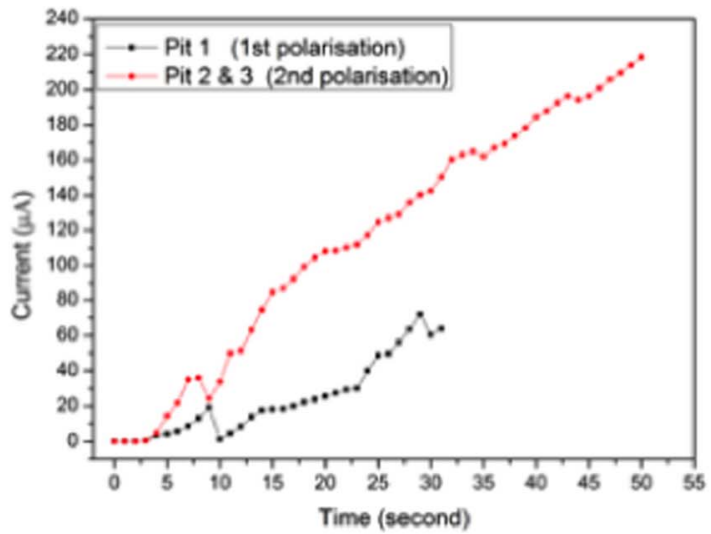

(a)

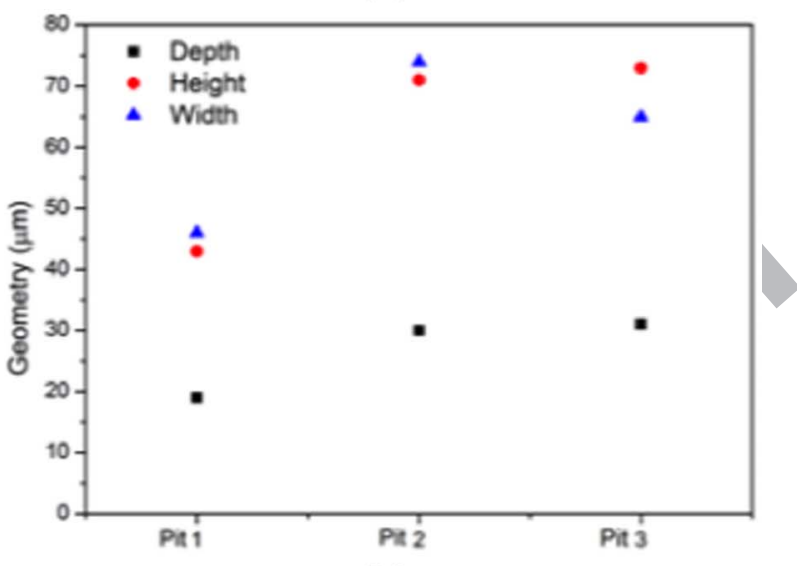

(b)

Figure 3. (a) Current evolution vs. time of the $1^{\text {st }}$ and $2^{\text {nd }}$ potentio-dynamic polarisation cycle with (b) measured depth (r), width (w) and height (h) of all three pits from X-ray CT data.

a 3-D view of the reconstructed tomography data of the wire with pit 211 1 , and Figure $2 \mathrm{~b}$ gives the same volume with all 3 pits, recorded after 212 the $2^{\text {nd }}$ polarisation cycle. The final polarisation cycle (step 8) did not 213 result in the formation or further growth of corrosion pits. A SEM 214 image of the wire after the test is shown in Figure 2c.

Electrochemical polarisation.-The OCP prior to the first polari- 216 sation was $+129 \mathrm{mV}$ vs $\mathrm{Ag} / \mathrm{AgCl}$ (Step 1), with an OCP prior to the 217 second scan of $+151 \mathrm{mV}$ (step 4). The current evolution over time 218 of the first and second potentio-dynamic scan are shown in Figure 219 3a. During the first polarisation cycle, the current started to rise at 220 $+616 \mathrm{mV}$ up to the applied max. potential of $+644 \mathrm{mV}$ vs. $\mathrm{Ag} / \mathrm{AgCl}$. 221 The second polarisation resulted in a current increase starting at $+596 \quad 222$ $\mathrm{mV}$ but with a far steeper rise of current over time, resulting in ap- 223 proximately double the gradient compared to the current evolution 224 observed during the first polarisation cycle. Both curves show a drop 225 of current after a few seconds followed by a continuous rise again. $\quad 226$

The shift in OCP after the first polarisation is either due to the 227 growth of the passive surface film, often associated with anodic po- 228 larisation of passive material, or alternatively an effect of the high 229 energy X-ray beam, causing chemical changes of the film/electrolyte 230 interface. This shift is also observed after the second X-ray CT scan 231 (step 6) with an OCP recorded of $+178 \mathrm{mV}$ vs. $\mathrm{Ag} / \mathrm{AgCl}$. A third 232 polarisation cycle (step 7) was performed from OCP up to $+700 \mathrm{mV}, \quad 233$ but no measurable current increase over time was observed. No fur- 234 ther pit was nucleated during this cycle, which may be related to the 235 limited number of active sites of inclusions at this potential.

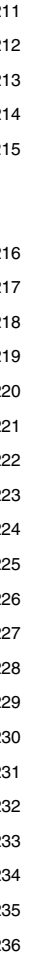


Table II. Measured pit geometries.

\begin{tabular}{|c|c|c|c|c|c|c|c|c|c|}
\hline \multirow[b]{2}{*}{ Methods/pit parameters } & \multicolumn{3}{|c|}{$\begin{array}{l}\text { A-measured data } \\
\text { from X-ray CT scans }\end{array}$} & \multicolumn{3}{|c|}{$\begin{array}{c}\text { B - depth measured by X-ray } \\
\text { CT + assumption of a } \\
\text { hemi-spherical pit shape }\end{array}$} & \multicolumn{3}{|c|}{$\begin{array}{l}\text { C- Faraday approach } \\
+ \text { assumption of a } \\
\text { hemi-spherical pit shape }\end{array}$} \\
\hline & Pit 1 & Pit 2 & Pit 3 & Pit 1 & Pit 2 & Pit 3 & Pit 1 & Pit 2 & Pit 3 \\
\hline Depth, $\mathbf{r}(\mu \mathrm{m})$ & 19 & 30 & 31 & 19 & 30 & 31 & $22.7^{*}$ & 35.8* & $35.8^{*}$ \\
\hline Width, w $(\mu \mathrm{m})$ & 43 & 71 & 74 & $38^{*}$ & $60^{*}$ & $62^{*}$ & $45.4^{*}$ & 71.6* & 71.6* \\
\hline Height, $\mathbf{h}(\mu \mathbf{m})$ & 46 & 73 & 65 & $38^{*}$ & $60^{*}$ & $62^{*}$ & $45.4^{*}$ & 71.6* & 71.6* \\
\hline
\end{tabular}

* assumed values in bold.

Pit geometry and estimation of growth kinetics.-The pit dimensions at the end of the polarisation with depth, width and height obtained from measurements of the X-ray CT data are shown in Figure 3b. All pit volume and surface parameters measured via segmentation are summarised in Table II. Beside the direct measurements from X-ray CT data, two additional geometrical approaches (B and C) were also explored to estimate pit growth kinetics. Table I lists the parameters of all 3 approaches, which were applied to simulate pit growth kinetics.

In approach $\mathrm{A}$, all values were measured from segmented X-ray CT data. The area of the pit surface was obtained by measuring the surface area of the segmented pit volume, excluding the area of the pit mouth. This represented the real area of the pit internal surface assuming the pit cover is passive. In the case of pits 2 and 3 , the similar size of both segmented volumes from X-ray CT data, in combination with the current evolution over time implied that both had nucleated at the same time during the $2^{\text {nd }}$ polarisation scan. This assumption of simultaneous pit growth then allowed the current in Figure 3a to be equally divided between pit 2 and 3 , which is supported by the observed current over time gradient, i.e. approximately double that observed for the growth of pit 1 .

In approach B, the pit volume and surface area were calculated by assuming the pit shape is hemi-spherical with only the pit depth (r) obtained from the X-ray CT measurements. The computed volume (V) of the hemisphere followed the equation $V=2 / 3 . \pi .(r),{ }^{3}$ with the development of the surface area determined by assuming isotropic growth from a local initiation point at the centre of the hemi-sphere diameter. To determine evolution of pit surface area over time, it was assumed that pits were active at the end of the polarisation cycle. This is supported by the current response in Figure 3a. Assumption of symmetric growth of the pit volume then allowed back extrapolation of the pit surface area from the end of the polarisation scan to the point where the current started to rise. This assumption is based on a mean current density over the entire pit surface area to satisfy homogeneous growth of both, the pit surface area and pit volume. However, this also allowed comparison of the measured current response in Figure 3a, by computing the measured current over the estimated surface area for each point in time, shown as current density plots in Figures $4 \mathrm{a}$ and $4 \mathrm{~b}$. Comparison of the behavior of pits observed in this study then allowed trends of current density and associated stability product values over time to be identified (Figure 4).

In approach $\mathrm{C}$, the pit volume was calculated from the charge passed during the period of pit growth in Figure $3 \mathrm{a}$ and converted into mass using Faraday's law. The metal dissolution assumed an average metal cation charge of $\mathrm{n}=2.19$, atomic weight $\mathrm{M}=55.79 \mathrm{~g} \cdot \mathrm{mol}^{-1}$ and density of $\rho=7.97 \mathrm{~g} . \mathrm{cm}^{-3}$, and Faraday's constant $\mathrm{F}=96485$ coulomb/mol. ${ }^{12}$ Also a hemispherical pit shape was assumed, with a radius based on the dissolved volume (Table II). The development of the pit surface area for estimating the corresponding current densities was also based on a homogeneous symmetric growth, as described for approach B. From the current-time response in Fig. 3a, the pit current density and pit stability product over time were estimated (Figure 4).
Table II indicates that pit volumes calculated via segmentation 290 (approach A) are close to those calculated via Faraday's law (approach 291 C), with a difference of less than 6\%. This difference may be explained 292 with uncertainty in segmented X-ray CT data. Likewise, the small 293 contribution to the overall current density from the passive surface of 294 the wire was also not considered in these calculations.

By only considering the measured X-ray CT data of approach A, 296 the relationship of growth in pit depth over time can be determined, 297 corresponding to $r=a \cdot t^{x}$, where (r) represents pit depth, (a) and 298 (x) empirical pit growth constants, and $(t)$ time. Computing the pit 299 depths for all 3 pits gives similar values for (x), confirming that pit 300 growth kinetics for all 3 pits were similar. For achieving $t^{0.5}$ a pit 301 growth constant (a) of between $3-5 \times 10^{-6} \mathrm{~m} . \mathrm{s}^{-1}$ would need to be 302 assumed, which is in the range of typical growth constants reported. ${ }^{32}{ }_{303}$ This indicates that the pit depth growth rate in 3-D was possibly under 304 diffusion control, similar to the reported $t^{0.5}$ of diffusion control for 305 $1-\mathrm{D}^{33}$ and for $2-\mathrm{D}^{7}$ pit depths. The 3-D pit lateral growth by assuming 306 $(r)$ is the width $(\mathrm{w})$ and height $(\mathrm{h})$, show a relation with time of $>\mathrm{t}^{0.5} . \quad 307$ This implies that the width grew in a less than saturated solution faster 308 than the depth, which is also supported by the overall dimensions 309 obtained.

Figure $3 \mathrm{~b}$ shows a slight variation between pit width and height 311 for pit 1 and 2 compared to pit 3 . This indicates that all the pits shape 312 are not hemispherical, with 2-D X-ray CT slices showing an semi- 313 ellipsoid dish shape. The ratio of pit depth over width is in the range 314 of 0.41 and 0.47 , fitting well with reported values of 0.4 to $0.5 .^{13,34} 315$

Current density and stability product.-In order to obtain pit 316 growth rates, the current densities in Figure 4a have been calculated by 317 using the obtained current response of Figure 3a, divided by internal 318 pit surface area. Three values of pit current density over time are ${ }_{319}$ presented based on the three approaches A, B and C outlined in ${ }_{320}$ Table II.

Figure 4a shows mean current density as a function of time for 322 pit 1 . Two regions can be distinguished: the first where the current ${ }_{323}$ density increases rapidly and the second where it starts to drop over 324 time. Fluctuations in current density also become smaller over time. 325 The two regions consist of a transient and quasi-steady state period 326 which have been reported for pit growth. ${ }^{33}$ The maximum current ${ }_{327}$ density of pit 1 reached $5{\mathrm{~A} . \mathrm{cm}^{-2}}$ at the transient region for approach ${ }_{328}$ A, reducing to a mean value of $1.8 \mathrm{~A} . \mathrm{cm}^{-2}$ in the steady state region. $\quad 329$ Figure $4 \mathrm{~b}$ shows the results for pit 2 and 3 . The behavior of pit current 330 density over time is similar to pit 1 , but the time for pit growth was ${ }_{331}$ almost doubled. The results also show a limiting current density of 5 A. $\mathrm{cm}^{-2}$ for approach A, similar to the maximum value observed for ${ }_{333}$ pit 1 . At the end of the polarisation scan, a mean current density of ${ }_{334}$ $1.3 \mathrm{~A} . \mathrm{cm}^{-2}$ was estimated.

In Figures $4 \mathrm{a}$ and $4 \mathrm{~b}$, approach $\mathrm{A}$ has the lowest current densities 336 of all three approaches, indicating that the real pit surface area must ${ }_{337}$ be larger relative to the assumptions in approach B, with approach C 338 overestimating the pit depth compared to the real pit dimensions (Table 339 II). The difference in current density between approach A and B is 340 nearly $50 \%$, whereas for $\mathrm{A}$ and $\mathrm{C}$ it is only $6 \%$. An increase of current 341 

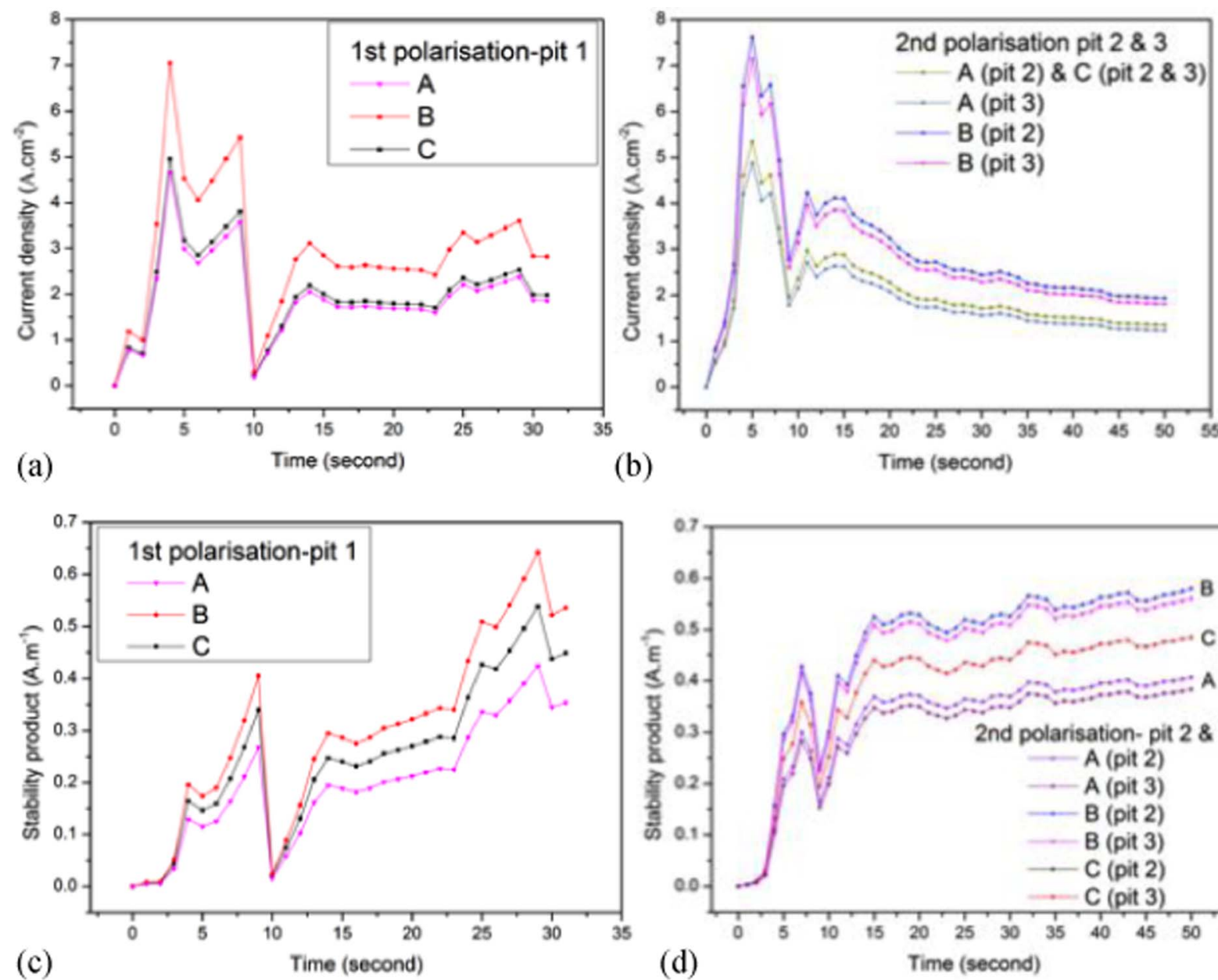

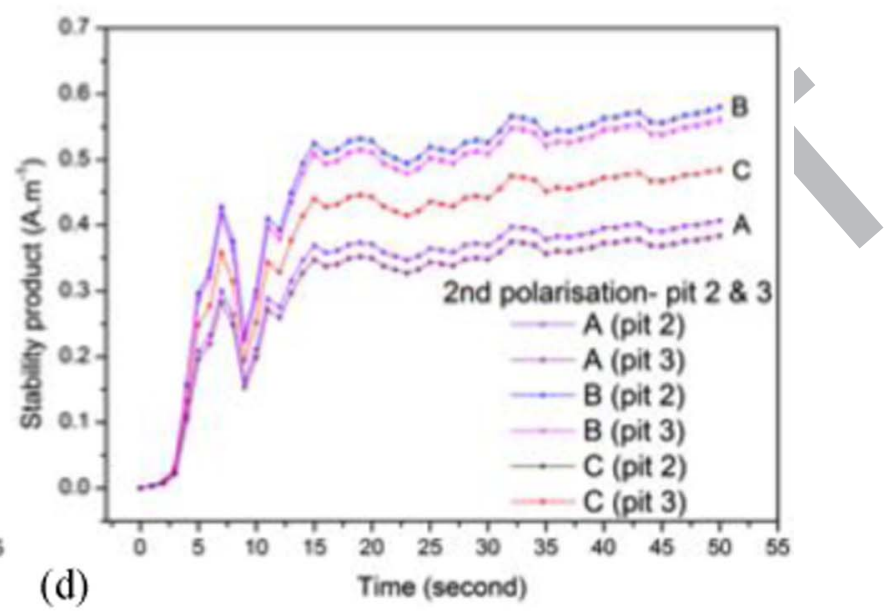

Figure 4. The values in Table II of the three approaches A, B, and C are applied to show (a) pit 1 current density vs. time, (b) pit 2 and 3 current density vs. time, (c) pit stability product vs. time of pit 1, and (d) pit stability products vs. time of pit 2 and 3 .

342 density with increasing polarisation time up to the maximum current 343 value under activation polarisation in the transient stage, and after that 344 the thickness of salt film precipitation affects pit growth. ${ }^{35}$ A sharp 345 drop in current density was observed at the transition between both 346 stages, which may indicate that dissolved metals ions reach saturation 347 and salt film precipitation occurs, reducing the measured current at 348 this stage to very low values. Longer pit growth periods clearly show 349 a quasi-steady state of current density. The difference in calculated 350 current density between approach A and approach B and C show that 351 longer pit growth periods in Figure $4 \mathrm{~b}$ reduce the difference between 352 them to less than $3 \%$.

$353 \quad$ Figures $4 \mathrm{c}$ and $4 \mathrm{~d}$ show the value of stability products as a function 354 of time for all three pits obtained by the three approaches. Stable pits 355 should have a stability product range of $0.3<$ i.r $<0.6{\mathrm{~A} . m^{-1}}^{12}$ Pit 356 stability values obtained by the three methods for all pits increased 357 over time, and fit in the range of stable pit criteria. However, the 358 result of approach A relative to approaches B and C show lower 359 stabilities of $25 \%$ and $50 \%$ respectively. The results also show that 360 pit stability product was initially below the stable pit growth crite361 ria, and then increased with time. At an early stage of pit growth, 362 the pit stability product was below 0.3 , and pit growth is then be363 lieved to be supported by a diffusion barrier in the form of lacy metal 364 covers. $^{12}$ It should be noticed that the above criteria were developed 365 by Pistorius and Burstein for stainless steel in chloride electrolytes, 366 assuming hemispherical open pit growth and $3 \mathrm{M}$ concentration as 367 a minimum for metal ion dissolution for metastable to stable pit 368 transition. The measurement also assumed a diffusion coefficient of $369 \mathrm{D}=1 \times 10^{-5} \mathrm{~cm}^{2} \cdot \mathrm{s}^{-1} \cdot{ }^{12,20}$
Comparing the above three approaches in our study, the results 370 indicate that the current density and pit stability product show slight 371 differences. This variation can be related to pit shape differences and 372 the effect of non-uniform dissolution on the local chloride concentra- 373 tion. It appears that using 2-D methods leads to an overestimate in the 374 pit depth growth rate as compared to that obtained from a 3-D analysis 375 of current density and associated stability products.

Pit diffusion product estimations.-Figure 5 shows the relation- 377 ship between the square of the pit depth $\left(\mathrm{r}^{2}\right)$ over time $(\mathrm{t})$ using Equa- 378 tion 1 (derived from Fick's first law and Faraday's second law), which 379 suggests that pit growth with salt layer is under diffusion control. The 380 equation shown below was used to estimate pit diffusion product. ${ }^{9,12}$

$$
r^{2}=((3 \cdot M \cdot D \cdot \Delta C) / \pi . \rho) \cdot t
$$

Where, $\mathrm{D}$ is the effective diffusion coefficient and $\Delta C$ is concentration 382 difference between pit bottom and mouth. The gradients in Figure 5383 provide the diffusion product (D. $\Delta$ C) with $1.68 \times 10^{-8}, 2.84 \times 10^{-8} \quad 384$ and $3.04 \times 10^{-8}$ mol.cm ${ }^{-1} \mathrm{~s}^{-1}$ for pits 1,2 and 3 , respectively, by using 385 the pit depths of the segmented volumes in approach A. These show 386 linear relationship between square depth of pits and time, suggesting 387 diffusion controlled pit growth in all cases. The obtained slopes are 388 lower than those reported for diffusion controlled pit growth in 1-D, ${ }^{7,36}{ }_{389}$ but similar to 2-D pit growth studies facing upward diffusion. ${ }^{9}$ Open 390 pit growth in 1-D with pits facing upwards, typical diffusion product 391 values close to $6 \times 10^{-8} \mathrm{~mol} \cdot \mathrm{cm}^{-1} \cdot \mathrm{s}^{-1}$ were obtained in $1 \mathrm{M} \mathrm{NaCl} 392$ solution, ${ }^{19}$ whereas, 2-D pit growth in $0.1 \mathrm{M} \mathrm{NaCl}$ with pits facing 393 upwards and lacy metal covers showed values similar to our results for 394 

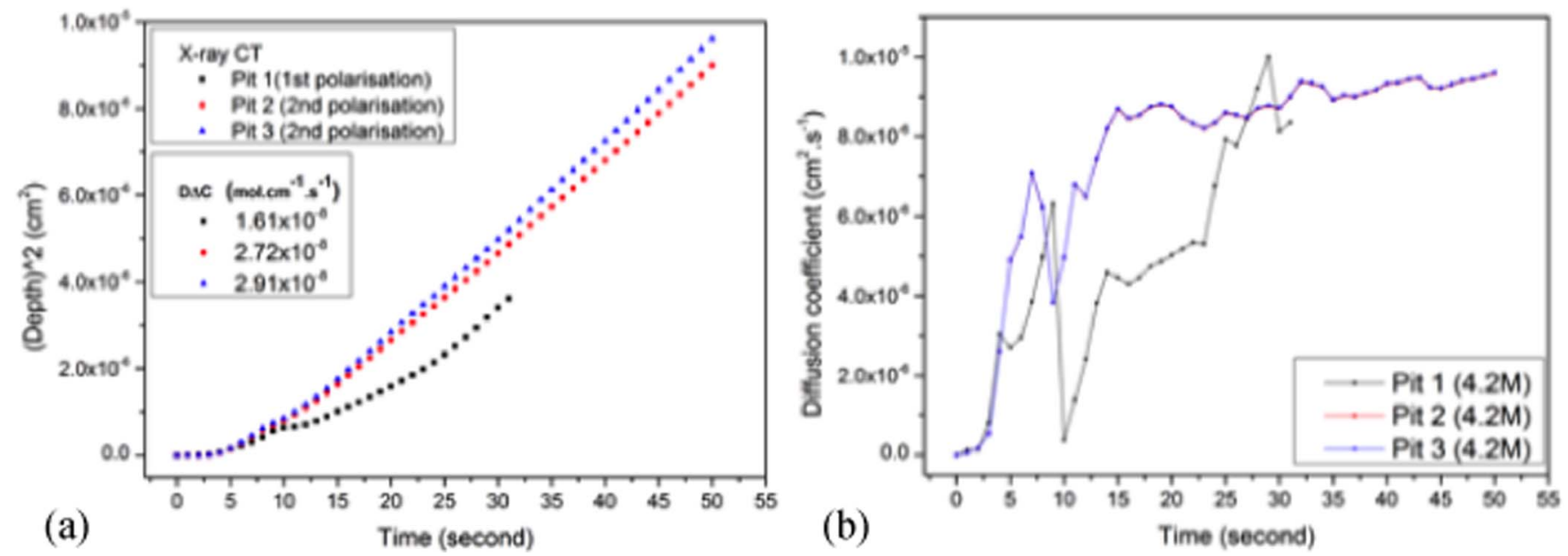

Figure 5. Effect of time on (a) (pit depth) ${ }^{2}$ to obtain the diffusion parameters of these curves from the slopes, (b) effective diffusion coefficient (D) estimated with a constant metal ion concentrations of $4.2 \mathrm{M}$.

395 pits 2 and $3 .{ }^{9}$ It may be possible that $3-\mathrm{D}$ pit growth and vertical sample 396 position allows the electrolyte to be more easily infused by gravity, 397 relative to $1-\mathrm{D}$ and $2-\mathrm{D}$ experimental set-ups, where the electrolyte 398 within the pit is constrained by pit geometry and sample position. ${ }^{37}$

399 In our study, pit 1 shows a lower diffusion product relative to pits 4002 and 3, possibly due to the influence of the lacy cover observed for 401 pits 2 and 3 (Figure 2c), affecting the anolyte concentration inside 402 the pit. A number of factors were suggested to influence the gradi403 ent of pit growth, such as the area of perforation of the metal lacy 404 covers, chloride concentration, applied potential, type of electrolyte 405 and temperature, as well as pit growth direction, with respect to the 406 sample position. ${ }^{7,9,14,19,21,23,38,39}$ For example, a difference of $15 \%$ was 407 reported between pit growth with the sample facing upwards versus 408 downwards in 2-D. ${ }^{7}$ In our study, all pits grew vertical at the wire, and 409 minor differences in diffusivity parameters estimated for pits 2 and 3 410 may even be a result of the difference in perforated area of both pit 411 covers. $^{9}$

412 If the diffusion coefficient (D) is assumed to be constant at 0.85 $413 \times 10^{-5} \mathrm{~cm}^{2} \cdot \mathrm{s}^{-1}, 9,17$ the mean metal salt concentration inside the pits 414 can be estimated from the diffusivity parameters given above. The 415 mean concentration would therefore be around $1.97 \mathrm{M}, 3.34 \mathrm{M}$ and 416 $3.57 \mathrm{M}$ for pits 1, 2 and 3, respectively. These values indicate that the 417 mean concentration at the pit bottom for pit 1 is below the $3 \mathrm{M}(75 \%$ 418 of saturation concentration of $\mathrm{FeCl}_{2}$ ) suggested for stable growth 419 facing upwards in type 304 stainless steel. ${ }^{12}$ It was also suggested 420 that stable pits can propagate without lacy covers, as the pit depth 421 also provides a diffusion barrier to maintain the corrosive solution for 422 active pit dissolution. This would mean that in our case pit 1 propagates 423 without lacy metal cover in $1.97 \mathrm{M}$ metal salt concentration with a pit 424 depth of $19 \mu \mathrm{m}$ acting as effective diffusion barrier to support stable 425 pit propagation after the pit lost its lacy cover. This concentration 426 is close to the reported values of $1.8-2 \mathrm{M}$, defined as critical ion 427 concentration for stable pit transition in stainless steel at constant 428 potentials. $^{40}$ Furthermore, it is shown that losing the lacy metal cover 429 certainly affects the ion concentrations inside pits, since pit 2 and pit 4303 show far higher concentrations of $3.34 \mathrm{M}$ and $3.57 \mathrm{M}$, respectively, 431 with both growing to similar depths of roughly $30 \mu \mathrm{m}$.

432 However, comparison of the growth kinetics of pits by assuming a 433 constant diffusion coefficient is not correct, since the effect of chloride 434 concentration and its change over time need to be taken into consid435 eration. The effect of chloride concentration can be shown, for exam436 ple, by assuming a constant metal ion concentration inside the pit of $4374.2 \mathrm{M}$ throughout the pit growth period. This would result in our case 438 in mean diffusion coefficients of $0.4 \times 10^{-5}$ for pit 1 , and $0.68-0.72 \times$ $43910^{-5} \mathrm{~cm}^{2} . \mathrm{s}^{-1}$ for pits 2 and 3 , based on the above diffusivity products

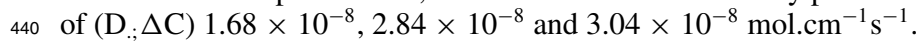

Alternatively, the variation of effective diffusivity (D) with pit 441 growth over time can be estimated using Equation 2, ${ }^{20}$ with the results 442 summarised in Figure 5b.

$$
\Delta C=(2 \pi /(3 n . F . D)) i . r
$$

This gives a realistic approach of the effect of time, by considering 444 (D) as Key variable, and using the evolution of current density (i) 445 and pit depth (r) over time from approach (A) as input parameters. 446 The saturation concentration $(\Delta C)$ was kept constant at 4.2 M. Figure 447 $5 \mathrm{~b}$ clearly shows a large variation of diffusion coefficients during the 448 initial transient stage, which is most likely caused by overestimating 449 the metal ion concentration inside the pit. In reality, lower metal ion 450 concentrations than the one used in this estimation will be present, 451 ultimately resulting in the formation of lacy metal covers.

Interestingly, effective diffusion coefficients of $0.83 \times 10^{-5}$ for ${ }_{453}$ pit 1 and $0.96 \times 10^{-5} \mathrm{~cm}^{2} \cdot \mathrm{s}^{-1}$ for pit 2 and 3 are obtained for the steady 454 state pit growth period in Figure 5b, which is close to the estimated 455 diffusion coefficient for 1-D and 2-D pit growth studies. ${ }^{20,33}$ The drop 456 of diffusion coefficient between 7-9 second for all pits may indicate 457 salt film precipitation and for pit 1 this may be associated with the 458 time where pit 1 lost its lacy metal cover as seen in Figure 2c.

This study shows that quasi in-situ X-ray CT experiments provide an effective tool to study pit growth kinetics and to probe assumptions for optimising pit kinetics for predicting material behavior. The advantage of the 3-D approach over previous 1-D and 2-D in-situ approaches lies in the reduction of geometrical constraints, by studying real 3D systems. Further experiments are currently conducted with this approach, by inducing nucleation and growth of multiple pits, to understand whether these affect each others growth kinetics, and the influence of strain on pit growth.

\section{Conclusions}

1. 3-D pit growth kinetics can be estimated via quasi in-situ measurements from electrochemical polarisation tests with information of pit dimensions using X-ray CT data. The pit volumes obtained by $\mathrm{X}$-ray CT showed good fit with the volume of metal dissolution calculated using Faraday's law.

2. The measured surface area of pits from X-ray CT is larger than those calculated by assuming hemispherical pit growth, with pits approaching elongated dish shapes rather than perfect hemispherical shapes.

3. Typical mean current densities of 1-3 A.cm ${ }^{-2}$ with pit stability product of $0.3-0.6 \mathrm{~A} . \mathrm{m}^{-1}$ have been estimated for stable pit growth. Diffusivity parameter (D. $\Delta$ C) between $1.68-3.04 \times 10^{-8}$ mol.cm ${ }^{-1} . \mathrm{s}^{-1}$ were obtained. 
483 4. Pit growth rates in 3-D indicate that the pit depth is under diffusion $484 \quad$ control, whilst lateral growth occurred faster.

485 5. Effective diffusion coefficients (D) from the pit base to the pit 486 mouth were estimated at $0.83 \times 10^{-5}$ and $0.96 \times 10^{-5} \mathrm{~cm}^{2} . \mathrm{s}^{-1}$ 487 for pit growth with assumed metal ion concentrations of $4.2 \mathrm{M}$.

\section{Acknowledgment}

The authors acknowledge the provision of beam time at Henry Moseley X-ray imaging Facility (HMXIF) at the University of Manchester, UK, established with funding from EPSRC through grants EP/F007906, EP/I02249X and EP/F028431. The authors would also like to thank Saline Water Conversion Corporation (SWCC), Saudi Arabia for financial support. Valuable discussions with Dr Anthony Cook (University of Manchester) are also acknowledged.

\section{References}

496 1. G. Frankel, J Electrochem Soc, 145(6), 2186 (1998).

497 2. Z. Szklarska-Smialowska, Corrosion, 27(6), 223 (1971).

498 3. T. P. Hoar and W. R. Jacob, Nature, 216(5122), 1299 (1967).

499 4. N. Sato, Corrosion Sci., 37(12), 1947 (1995).

500 5. H. Isaacs and G. Kissel, J Electrochem Soc, 119(12), 1628 (1972).

501 6. J. Mankowski and Z. Szklarska-Smialowska, Corrosion Sci., 15(6), 493 (1975).

502 7. P. Ernst and R. C. Newman, Corrosion Sci., 44(5), 927 (2002).

503 8. S. M. Ghahari, A. J. Davenport, T. Rayment, T. Suter, J.-P. Tinnes, C. Padovani,

504 J. A. Hammons, M. Stampanoni, F. Marone, and R. Mokso, Corrosion Sci., 53(9), 2684 (2011).

9. M. Ghahari, D. Krouse, N. Laycock, T. Rayment, C. Padovani, M. Stampanoni, F. Marone, R. Mokso, and A. J. Davenport, Corrosion Sci., 10023 (2015).

10. N. J. Laycock and S. P. White, J Electrochem Soc, 148(7), B264 (2001).

11. N. J. Laycock, S. P. White, J. S. Noh, P. T. Wilson, and R. C. Newman, J Electrochem Soc, 145(4), 1101 (1998).

11 12. P. C. Pistorius and G. T. Burstein, Philos T Roy Soc A, 341(1662), 531 (1992).

512 13. R. C. Alkire and K. P. Wong, Corrosion Sci., 28(4), 411 (1988).

513 14. N. J. Laycock and R. C. Newman, Corrosion Sci., 39(10-11), 1771 (1997).

514 15. R. C. Newman and E. M. Franz, Corrosion, 40(7), 325 (1984).
16. J. González-Sánchez, L. Dzib-Pérez, E. Garcia-Ochoa, G. Canto, and M. Sosa-Baz, Anti-Corros Method M, 59(5), 239 (2012).

17. G. T. Gaudet, W. T. Mo, T. A. Hatton, J. W. Tester, J. Tilly, H. S. Isaacs, and R. C. Newman, Aiche J, 32(6), 949 (1986).

18. U. Steinsmo and H. S. Isaacs, Corrosion Sci., 35(1-4), 83 (1993).

19. M. H. Moayed and R. C. Newman, Corrosion Sci., 48(11), 3513 (2006).

20. P. C. Pistorius and G. T. Burstein, Corrosion Sci., 33(12), 1885 (1992).

21. G. S. Frankel, Corrosion Sci., 30(12), 1203 (1990).

22. W.-M. Tian, Y.-J. Ai, S.-M. Li, N. Du, and C. Ye, Acta Metallurgica Sinica (English Letters), 28(4), 430 (2015)

23. W. Tian, S. Li, N. Du, S. Chen, and Q. Wu, Corrosion Sci., 93(0), 242 (2015).

24. N. Aouina, F. Balbaud-Célérier, F. Huet, S. Joiret, H. Perrot, F. Rouillard, and V. Vivier, Electrochimica Acta, 104(0), 274 (2013).

25. S. M. Ghahari, D. P. Krouse, N. J. Laycock, T. Rayment, C. Padovani, T. Suter, R. Mokso, F. Marone, M. Stampanoni, M. Monir, and A. J. Davenport, Corros Eng Sci Techn, 46(2), 205 (2011).

26. A. B. Cook, D. L. Engelberg, N. P. Stevens, N. J. Laycock, S. White, M. Ghahari, M. Monir, H. J. Holroyd, and R. C. Newman, ECS Transactions, 41(25), 121 (2012).

27. T. Burnett, S. McDonald, A. Gholinia, R. Geurts, M. Janus, T. Slater, S. Haigh, C. Ornek, F. Almuaili, D. Engelberg, and P. J. Withers, Scientific reports, 4, 711 (2014).

28. A. King, G. Johnson, D. Engelberg, W. Ludwig, and J. Marrow, Science, 321(5887), 382 (2008).

29. T. J. Marrow, L. Babout, B. J. Connolly, D. Engelberg, G. Johnson, J. Y. Buffiere, P. J. Withers, and R. C. Newman, in Environment-Induced Cracking of Materials, S. A. Shipilov, R. H. Jones, J. M. Olive, and R. B. Rebak, eds., p. 439, Elsevier, Amsterdam, (2008).

30. L. Babout, T. J. Marrow, D. Engelberg, and P. J. Withers, Mater Sci Tech-Lond, 22(9), 1068 (2006).

31. L. Feldkamp, L. Davis, and J. Kress, JOSA A, 1(6), 612 (1984).

32. M. K. Cavanaugh, R. G. Buchheit, and N. Birbilis, Corrosion Sci., 52(9), 3070 (2010).

33. J. W. Tester and H. S. Isaacs, J Electrochem Soc, 122(11), 1438 (1975).

34. R. K. Ulrich and R. C. Alkire, Corrosion Sci., 23(11), 1153 (1983).

35. G. S. Frankel, J. O. Dukovic, V. Brusic, B. M. Rush, and C. V. Jahnes, J Electrochem Soc, 139(8), 2196 (1992).

36. M. H. Moayed and R. Newman, Materials and Corrosion, 56(3), 166 (2005).

37. J. Mankowski and Z. Szklarskasmialowska, Corrosion Sci., 17(9), 725 (1977)

38. H. C. Kuo and D. Landolt, Electrochimica Acta, 20(5), 393 (1975).

39. A. G. Carcea, E. Y. Yip, D. D. He, and R. C. Newman, J Electrochem Soc, 158(6), C215 (2011).

40. N. Sato, J Electrochem Soc, 129(2), 260 (1982). 
Query

Q1: AU: Please provide text citation for refs. 22 and 24.

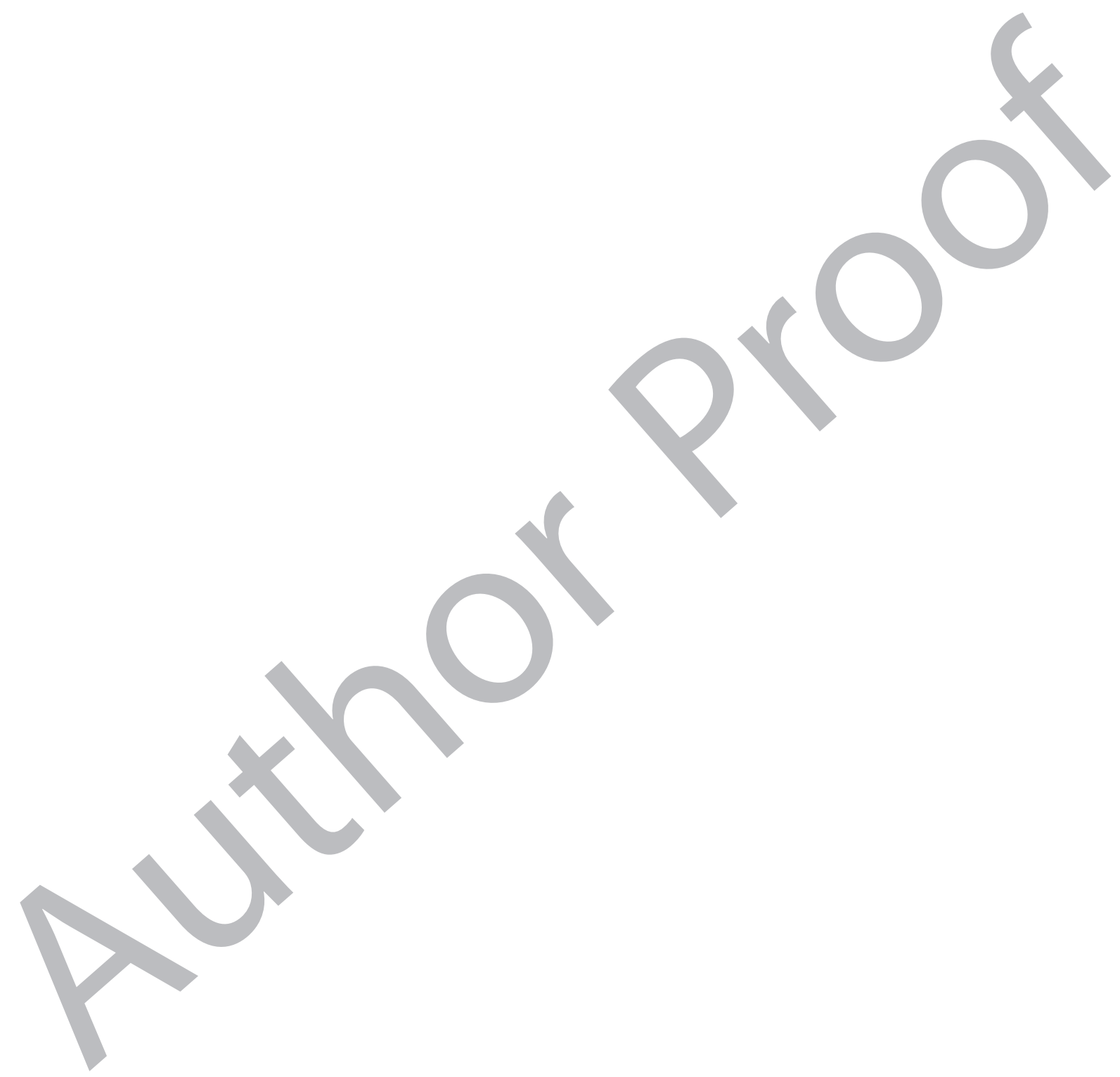

